\title{
From Brain Drain to Brain Gain: The Battle Against Talent Drain
}

\author{
Peter Ndiangui * \\ Florida Gulf Coast University \\ *Corresponding Author: pndiangui@fgcu.edu \\ Received : 2019-10-28 \\ Rev. Req. : 2019-12-10 \\ Accepted : 2020-01-24
}

$10.46303 /$ jcve. 2020.5

\begin{abstract}
How to cite this paper: Ndiangui, P. (2021). From Brain Drain to Brain Gain: The Battle Against Talent Drain. Journal of Culture and Values in Education. 4(1), 34-48. https://doi.org/10.46303/jcve.2020.5

This is an Open Access article distributed under the terms of the Creative Commons Attribution 4.0 International license (https://creativecommons.org/licenses/by/4.0/)
\end{abstract}

\section{Abstract}

Building an enabling scientific community of educated or professional people is a growing focus for many American cities. The retention of home-grown graduates increases the intellectual capacity in a region. Arising from technology-driven accelerated growth, the geographical mobility of young skilled workers has become a key issue in recent studies, attracting the attention of both academics and policymakers. The purpose of this paper is to investigate the factors that influence the retention or draining of graduates from a mid-sized higher education instruction's Child and Youth Studies (CYS), an innovative transformational educational program. The program is focused on developing a socially entrepreneurial mindset on the part of the learner. The study is also aimed at identifying how urban areas in southwest Florida would work toward retaining a large pool of young innovative graduates and enjoy the benefits of smart growth. The data for the study was collected by sending out a survey to 115 current students or those who are about to graduate. The selected 50 (43.5\%) participated in the study by completing the survey. The data was analyzed using several descriptive statistics. Several retention factors were identified. They included socio-economic and recreational factors. The research found that the majority of the graduates left not just because it was not easy to find competitive-paying jobs in the region but rather because of lack of awareness of the availability. Other significant factors included inadequate housing, lack of support for their entrepreneurial incubators, and poor public transport. It was also evident that a large number of potential local employers were not aware of the benefits of hiring the CYS graduates. Greater involvement of college students and recent graduates in the community projects would increase retention. It is proposed that each of the SW Florida cities should develop policies that will make them more attractive to the graduates. They should also identify ways of increasing awareness of opportunities available for the graduates in the region. 
Ndiangui, P. (2021). From Brain Drain to Brain Gain: The Battle Against Talent Drain

Keywords: Retention, Brain Drain, Brain Gain

\section{Introduction}

According to reports from the Population Reference Bureau (PRB), demographic data has shown that Florida State is the undisputed ultimate retirement destination. This is largely because, over the years, Florida was (and still is) the leading state in attracting an ageing population (Himes, 2003). It leads in the states with the highest percentage of ageing inbound migrants. More than 2.8 million people (17.6\% of the total population) are over the age of 65 , and the rate of increase of this ageing population is the highest in the country. Whereas this is seen as good in the fact that the state gets a lot of "old money," several studies (Florida, 2016; Lima, 2014; Schmidt, 1998) have concluded that, in order to have smart growth, every region should strive to attract a younger, more technologically savvy population. The growth of a significant proportion of the population comprised of college graduates is often associated with accelerated economic growth. It has also been noted that it is economically beneficial to retain those graduating from colleges located in the region (Lima, 2014). In order to have smart growth, it is important for regions to have policies to retain the students graduating from colleges located in the region. Such policies should be geared toward controlling the talent drain from the region. The term "talent drain" is used as synonymous with the movement of talented human capital, where the net flow of expertise is heavily in one direction (Salt, 1997).

This paper investigates the factors that may influence the retention in southwest (SW) Florida of graduates from the Child and Youth Studies (CYS) studies program at a public university in SW Florida. The research findings will be used to make recommendations on ways and means in which the SW Florida community could increase the retention of graduates of the very innovative CYS program in the university's College of Education. This is largely because, in several parts of the developed world, universities and colleges have served as major catalysts of the economic development of cities and metro areas (Florida, 2016). For example, Stanford is often credited as the innovative spur to the Silicon Valley, and MIT is seen as a catalyst for startups and high technology in and around Greater Boston. Retaining graduates from local colleges should therefore be a priority for forward-looking cities. Studies have shown that having a large group of graduates in any economy is in itself a stimulant to economic growth (Moretti, 2004). According to one study, the average bachelor's degree holder contributes $\$ 278,000$ more to local economies than the average high school graduate through direct spending over the course of his or her lifetime. An associate degree holder contributes $\$ 81,000$ more than a high school graduate (Rothwell, 2015). In the last two decades, many states have developed programs that support local students with the hope that they will stay in the state upon graduation. Since Georgia introduced its HOPE Scholarship in 1993, several states have followed with similar programs (Groen, 2004). In 1997, Florida developed its Bright Futures Scholarship program to emulate its northern neighbor. Bright Futures originally disbursed just over 42,000 scholarships for about $\$ 70$ million. At the program's peak in 2008, it provided scholarships to 39 percent of Florida high school graduates. Like in many other states, Bright Future Scholarships are awarded to state residents on the basis of academic achievement, as 
Ndiangui, P. (2021). From Brain Drain to Brain Gain: The Battle Against Talent Drain

measured by high school grades and standardized test scores. The primary objective of these merit-aid programs is to develop and retain college-educated workers in a state. This goal is based on two factors: First, evidence from cities suggests that the overall education level of an area increases the wages of all workers in the area (Moretti, 2004) and contributes to economic growth (Glaeser, Scheinkman, \& Shleifer, 1995). Also, college graduates earn more and therefore pay higher taxes to the state. Second, academically talented students often attend college outside their home state. A perception in many states is that talented students leave the state for college and do not return (Schmidt, 1998).

Traditionally, there has been a tendency of young graduates who complete their studies in a region to venture outside their college locations and seek their fortunes elsewhere (Lima, 2014). There is also a tendency of them returning home at middle age. Over the past decade or so, cities and metro areas across the United States have greatly increased their efforts to retain college graduates (Florida, 2016). This is largely because the graduates who have already lived in the region have developed it as a sense of place and are more likely to settle down easily. During this period of rapidly changing technology and innovativeness, college graduates are a key driver of innovation and economic development due to their adaptability to change. Similarly, most Americans are much more likely to move in their mid-to-late twenties, so the metro areas that hang on to more of their college graduates stand to gain a long-run advantage (Florida, 2016).

\section{Review of the Literature}

This paper adopts the approach of many other researchers who have been highlighted in this literature review. In the available literature, it is noted that some cities within which colleges are located are better off in attracting and retaining the local graduates than others. Rothwell (2015) conducted a study to determine the ability of a city or region to retain graduates. The likability criteria used in determining the attractiveness of a city for a graduate are jobs, affordability, and livability. Melton (2014) noted that the top three cities for college graduates are Madison, Wisconsin, Lincoln, Nebraska, and Minneapolis, Minnesota. The worst cities for college graduates are located in California, Florida, and throughout the Northeast. It should be noted that popular destinations for college graduates such as New York, San Francisco, Los Angeles, Seattle, Denver, and Austin were not at the top of the list due to their lack of affordability for those just starting their careers (Florida, 2016).

For the third straight year, U.S. News and World Report has placed Florida as the top state in the nation when it comes to higher education (U.S. News, 2019). According to the publication's website, those rankings include analysis of "the shares of citizens in each state holding a college degree, as well as the time it takes students to complete both two- and four-year college programs, the cost of in-state tuition and fees, and the burden of debt that college graduates carry."

Public institutions of higher learning are integral parts of the community in which they are located. Besides being bastions of local knowledge creation, universities increase local human 
Ndiangui, P. (2021). From Brain Drain to Brain Gain: The Battle Against Talent Drain

capital (Winters, 2011), a factor routinely found to directly increase economic growth. The production of highly qualified personnel is in itself a stimulant of economic growth and development. College grads are a key driver of innovation and economic development and are closely connected to the wealth and affluence of cities and metro areas (Florida, 2016). Many researchers have noted the high correlation between regional economic growth and higher educational attainment, which can be observed in the recent rise of metropolitan areas like San Jose, Austin, Washington D.C., and Boulder (Glaeser, Scheinkman, \& Shleifer, 1995; Moretti, 2004; Schmidt, 1998). Consequently, many regions have set up aggressive programs for the retention of graduates from local universities. This study focuses on the retention of graduates from a much-needed program in the region in which the college is located. It is part of the studies with retention as a theme. The majority of the studies (Noble, 2008) on retention tend to focus on students in college and employees in an organization. The majority of them have identified variables found to influence undergraduate retention.

The main factors identified include academic preparation. Bean (1980) stressed the importance of background characteristics including academic preparation prior to attending college or university. The quality of a student's prior instruction and his or her preparedness for collegelevel work can significantly influence whether or not a student will succeed at an institution of higher education.

Academic engagement and connection to the academic life of an institution has been related to undergraduate retention (Retention Study Group, 2004). An encouraging climate that promotes positive faculty-student interactions, as well as taking advantage of resources that promote academic success such as learning centers, tutorials, and office hours, have been demonstrated to positively influence retention (Habley, 2004; Wyckoff, 1998). This is in addition to academic support services that are linked to everyday learning in the classrooms of credit-bearing courses; the more likely students are to engage the services, the more likely they are to succeed (Tinto, 2004).

Social engagement during college was also identified as an important factor that influenced retention. Hone and EI Said (2016) noted that the students who were more involved in student activities that went beyond the college boundaries tended to understand the community better and were more likely to be retained. Dickinson and Perry (2002) observed that the graduates who were more likely to stay in a region had either worked or volunteered in the local organizations and become part of the community. They also noted that if students simply go to class and then go home without engaging in campus activities, they are less likely to be retained. For over 30 years, researchers and practitioners have been stressing the importance of successful social integration for student success. The establishment of friendships with peers, the development of mentors, and connections to faculty members have been identified as important factors for student integration (Swail, 2004).

The retention of graduates in the region in which the college is located is influenced by similar factors. For instance, Sung-Hyun Cho (2012) noted that the retention of nurses who grew up, graduated, and worked in the same region accounted for the greatest proportion (54 percent). 
Ndiangui, P. (2021). From Brain Drain to Brain Gain: The Battle Against Talent Drain

Sixty-five percent had their first employment in the region where they graduated. Nurses tended to move from poor to rich regions and from non-metropolitan to metropolitan areas.

Several studies have focused on the issues of brain drain and retention of graduates. Winters (2011) observed that after graduation, many recent in-migrants tend to move back to a previous location or to a new location. However, in places where good connections were made with future employers during the course of their studies, many graduates prefer to stay in the region where they studied. It is also a concern of city leaders in many parts of the country. Cities like Boston have made the ability to attract and retain college graduates an important public policy issue (Lima, 2014). A preoccupation with "talent drain" and "retention" is understandable given that a large population of younger, high-skilled, highly educated workers is a key factor in driving a city's economic growth, vitality, and per capita income (Moretti, 2012).

\section{The Child and Youth Studies Programs}

Throughout the United States, if not the entire world, there is a rapid decline in the number of students choosing education as a career (Paulsen, 1990). This, coupled with the rising population, puts a lot of pressure on teacher training institutions in not only in the recruitment and sustaining procedures but also in making the programs more appealing to young high school graduates. These more adaptable students would be more flexible in their engagement in the different community socioeconomic sectors. Young graduates are opting more and more for innovative programs that allow more flexibility in how they can put into practice what they learned in college.

The Child and Youth Studies (CYS) is a non-traditional teacher training program geared toward the attraction of those students who would like to teach but not be trapped in a classroom setting (FGCU College of Education website). They can also undertake other roles besides teaching. The courses taught widens the scope of their choices while at the same time being able to teach in regular and non-traditional classrooms. The CYS program in the selected SW Florida institution of higher learning prepares graduates for education, human services, community development, and different types of nonprofit and for-profit organizations. It is also designed to serve a larger population of future educators who may not desire to complete one of the College of Education's current state-approved teacher preparation programs, or students who want more than a minor in education and who want a program that includes an internship, or students who have a major not covered by one of the state-approved teacher preparation programs and who want to complete as much of the Florida teacher certification requirements as possible. "The Bachelor of Science degree in Child and Youth Studies is flexible enough to accommodate all of these populations while retaining the highest level of practice and pedagogy."

The Community Engagement concentration prepares graduates for leadership roles in informal learning environments such as youth organizations, museums, non-profit organizations, parks and recreation, and other community destinations. The CYS major prepares students to address the complex issues facing children, youth, families, and communities in the 21st century. For 
Ndiangui, P. (2021). From Brain Drain to Brain Gain: The Battle Against Talent Drain

example, the social entrepreneurship course is designed to equip learners with skills for initiating and upgrading innovative educational or community development programs. Students acquire critical skills to assist children, youth, families, and communities in meeting their needs, including: Interpersonal Communication, Leadership, Program Planning, Management, and Administration, Social Policy, Applied Research and Evaluation and Community-based Education. The program has two concentrations: the Education Studies concentration, which focuses on such courses as Learning Management, Professional Teaching Practice, Creative \& Affective Development, Play Development \& Assessment, and Cognitive Experience for Young Children and Young Children with Special Needs; and the Community Engagement concentration, which focuses on such courses as Social Entrepreneurship, Family \& Community Partnerships, Youth \& Community Resilience, Informal Learning Environments, Intro to Comparative Education and Youth \& Community Leadership (FGCU College of Education website).

\section{Research Questions}

The research questions for this study were sought as follows:

- What are the factors that influence the retention of CYS graduates in SW Florida?

- How does awareness of the CYS program through internships influence the retention of CYS graduates in SW Florida?

- What are the demographic characteristics that influence the retention of CYS graduates in SW Florida?

\section{Method}

A survey was sent to the 115 CYS students and graduates $(n=115)$ who graduated in the last three years and those about to complete the program by 2020. The survey contained seven closed-ended questions and four open-ended questions.

\section{Participants and Sampling}

The sample for this study was drawn from the student population of CYS graduates in a university located in SW Florida. The total number of those selected was $115(n=115)$. A total of 50 respondents (43.4\%) completed the survey. Of these, 43 (86\%) were females and 7 (14\%) were males. In terms of age, 38 (76\%) were below the age of 25 and only 5 were over the age of 32. Virtually all of them had undergone the CYS program at the same university. About $96 \%$ were born and raised in Florida.

A total of 32 (64\%) respondents were from SW Florida and another 16 (32\%) came from other parts of Florida. Only two (4\%) came from outside the state. A total of 26 (52\%) respondents chose to stay in SW Florida upon graduation. Others either planned to leave the state or were not decided. When asked why they wanted to leave the region, 33.3\% mentioned economic factors. Another $20 \%$ mentioned education opportunities outside the state. For those who chose to stay in SW Florida, $26 \%$ cited family ties and $13 \%$ mentioned environmental factors. 
Ndiangui, P. (2021). From Brain Drain to Brain Gain: The Battle Against Talent Drain

About 20\% mentioned that they were getting jobs in the region, which was the reason for choosing to stay.

Factors of retention: In the open-ended questions, the four commonly cited retention factors were more jobs, increase in incomes, more affordable housing, and better recreational opportunities.

Role of the internship in increasing awareness: When asked how the internship influenced the decision, several respondents noted that this was the most significant factor influencing the decision-making. They pointed out that it was a two-way process. The interns came to know about the opportunities available to them, and the organizations came to know more about the CYS program. Winters (2011) noted that recently acquired connections to employers seem to increase the likelihood of graduates staying in the region where they graduated. This helps smart cities to gain young innovative people.

\section{Data Collection and Analysis}

The survey instrument was sent out anonymously in March, 2019, to the 115 graduates who could be contacted. Of these, 50 responded-a 43\% return. Data was collected for a period of two months. The survey comprised a total of 11 items; seven of these were closed-ended and the remaining four were open-ended. The analysis was done using qualtrics. Largely, descriptive statistics was applied to analyze the data.

\section{Results}

Using qualtrics, an anonymous survey was sent to the 115 CYS students and graduates who graduated in the last three years and those about to complete the program by 2020. A total of $50(n=50)$ respondents (43.4\%) completed the survey. This return rate was considered adequate to provide a fairly representative sample.

\section{Demographic Effects on Decision to Stay or Leave}

The Chi Square analysis showed no significant effect of gender and reasons for leaving or staying in SW Florida (X-Square $=.10, \mathrm{df}=2$ and $p=0.92(>.05)$. The males were no more likely to leave than the females and vice versa. Similarly, in terms of age, Chi-Square $=7.91, \mathrm{df}=8$ and $\mathrm{P}$-value $=.47(\mathrm{P}>$.05). There was therefore no significant effect of age upon the reason to leave or stay. The study also examined if there was a significant relationship between where a participant was born and the decision to leave or stay. The Chi-Square $=7.88, \mathrm{df}=8$ and $\mathrm{P}$ Value $=0.45$. There was therefore no significant relationship between where one was born and the decision to leave or stay in SW Florida after graduating.

The study also examined whether the reason for majoring in CYS had something to do with the decision to stay or leave SW Florida upon graduation. The Chi Square $=17.16, \mathrm{df}=8$ and PValue $=0.03(P<.05)$. There was therefore a significant relationship between the reason why 
Ndiangui, P. (2021). From Brain Drain to Brain Gain: The Battle Against Talent Drain

somebody chose to major in CYS and the reason for deciding to stay or leave SW Florida. Evidently, the majority of those selecting CYS as a major did so in order to support the local SW Florida community. This is in line with the argument by Groen (2004) that the probability of college graduates staying in a region is influenced by their perception of opportunities within the region in which the college is located.

Table 1. Distribution of respondents by gender

\begin{tabular}{llll}
\hline Number & Answer & $\%$ & Count \\
\hline 1 & Male & $14.00 \%$ & 7 \\
2 & Female & $86.00 \%$ & 43 \\
& Total & $100 \%$ & 50 \\
\hline
\end{tabular}

From Table 1, it is evident that CYS attracts a lot more females than males. This is largely attributed to the fact that a number of traditional CYS programs are family-oriented. This was before the introduction of the Community Engagement concentration. It is hoped that there will be a better gender balance once the new concentration is fully implemented.

Table 2. Distribution of respondents by age

\begin{tabular}{lll}
\hline Age & $\%$ & Count \\
\hline 20 or younger & $4.00 \%$ & 2 \\
$21-24$ & $72.00 \%$ & 36 \\
$25-28$ & $10.00 \%$ & 5 \\
$29-32$ & $4.00 \%$ & 2 \\
Over 32 & $10.00 \%$ & 5 \\
Total & $100 \%$ & 50 \\
\hline
\end{tabular}

Of the 50 respondents, 43 (86\%) were females and 7 (14\%) were males. In terms of age, 38 (76\%) were below the age of 25 and only 5 were over the age of 32.

Table 3. Distribution of respondents by place of birth

\begin{tabular}{lll}
\hline Place of Birth & $\%$ & Count \\
\hline In SW Florida & $64.00 \%$ & 32 \\
In Florida but outside SW Florida & $32.00 \%$ & 16 \\
In US but outside Florida & $2.00 \%$ & 1 \\
Outside the US but in North America & $0.00 \%$ & 0 \\
Outside North America & $2.00 \%$ & 1 \\
Total & $100 \%$ & 50 \\
\hline
\end{tabular}

Of the 50 respondents, 48 (86\%) were born and brought up in the state of Florida with 32 (64\%) from SW Florida and another 16 (32\%) from other parts of Florida. Only two (4\%) came from outside the state. Attracting those born and raised in a region helps in minimizing the relocation 
Ndiangui, P. (2021). From Brain Drain to Brain Gain: The Battle Against Talent Drain

costs associated with getting labor from outside the state. This explains why it is essential to find ways of retaining graduates who are already acclimatized to the region.

Table 4. Reason for choosing the CYS program

\begin{tabular}{lcc}
\hline Reason for Choosing CYS & $\%$ & Count \\
\hline Wanted to work with children outside the classroom & $37.88 \%$ & 25 \\
Wanted to teach but did not pass some teaching preparation tests & $30.30 \%$ & 20 \\
Wanted to work with the community & $19.70 \%$ & 13 \\
It was the only choice available to me & $3.03 \%$ & 2 \\
Other reason (explain) & $9.09 \%$ & 6 \\
Total & $100 \%$ & 66 \\
\hline
\end{tabular}

As noted in Table 4, there were three main reasons why students chose to major in CYS. First, $38 \%$ of the participants wanted to train to work with children. A number of courses in the major focus on working with children in or outside the formal setting of a K-12 classroom. The program is particularly attractive to those who want to teach but not necessarily in a formal school environment. Secondly, unlike other teacher training programs, CYS students attain a Bachelor of Science degree and are not required to sit for the rigorous teacher preparation tests; of the participants, $30 \%$ did not want or were not prepared to take the subject tests and therefore chose to major in CYS. Third, about 20\% of the participants were students who were eager to work with communities. The new Community Engagement concentration is geared to preparing these students for community work. The remaining $12 \%$ had other personal reasons that included a desire to learn about the program without clear future plans.

Table 5. Plans for the future: Leave or settle

\begin{tabular}{lll}
\hline Where to settle after graduation & $\%$ & Count \\
\hline Settle in SW Florida & $52.00 \%$ & 26 \\
Leave SW Florida & $20.00 \%$ & 10 \\
Not decided yet & $28.00 \%$ & 14 \\
Total & $100 \%$ & 50 \\
\hline
\end{tabular}

A total of 26 (52\%) respondents chose to stay in SW Florida upon graduation. Others either planned to leave the state or were undecided. When asked why they wanted to leave the region, 33.3\% mentioned economic factors. Another 20\% mentioned education opportunities outside the state. For those who chose to stay in SW Florida, 26\% cited family ties and 13\% mentioned environmental factors. About $20 \%$ mentioned that they were getting jobs in the region, which was the reason for choosing to stay. 
Ndiangui, P. (2021). From Brain Drain to Brain Gain: The Battle Against Talent Drain

Table 6. Reasons for settling in SW Florida

\begin{tabular}{lll}
\hline Reason for choosing to settle in SW Florida & $\%$ & Count \\
\hline Socio-cultural factors - Family ties & $26.09 \%$ & 12 \\
Recreation opportunities & $8.70 \%$ & 4 \\
Personal factors - Positive experiences while in SW Florida (explain) & $15.22 \%$ & 7 \\
Other (specify) & $2.17 \%$ & 1 \\
Environmental factors - The weather & $13.04 \%$ & 6 \\
Education opportunities & $15.22 \%$ & 7 \\
Economic factors - Employment opportunities & $19.57 \%$ & 9 \\
Total & $100 \%$ & 46 \\
\hline
\end{tabular}

As noted in Table 6, about a quarter of all participants had cultural or family ties in SW Florida. They grew up there or their families immigrated to the region several years ago. About $13 \%$ prefer warm weather throughout the year and prefer to stay in the region. About $20 \%$ had jobs in the region. It is important for the community to increase this percentage by investing more in the region and letting the graduates know of the opportunities available for them. About 15\% stayed for educational reasons. These are the graduates who planned to undertake graduate courses at the local universities.

Table 7. Reasons for leaving SW Florida

\begin{tabular}{lll} 
Reason for choosing to leave in SW Florida & $\%$ & Count \\
\hline Socio-cultural factors - To reunite with family & $6.67 \%$ & 1 \\
Economic factors - Employment opportunities & $33.33 \%$ & 5 \\
Education opportunities & $20.00 \%$ & 3 \\
Recreation opportunities & $6.67 \%$ & 1 \\
Environmental factors - The weather & $0.00 \%$ & 0 \\
Personal factors - Negative experiences while in SW Florida (explain) & $0.00 \%$ & 0 \\
Other (explain) & $33.33 \%$ & 5 \\
Total & $100 \%$ & 15 \\
\hline
\end{tabular}

According to Table 7, a third of all the graduates chose to leave because of job opportunities outside the region. Another $20 \%$ chose to continue with their studies in universities located outside the region, and $6 \%$ were leaving because they wanted to reunite with their families outside the region.

\section{Open Text Responses}

This study had four open-ended questions. Of the 50 participants, 33 (66\%) completed all the questions. Another 14 (28\%) completed three questions fully. The analysis of these questions was based on the participants' responses from the questions. The first question was: "What do you think should be done to increase the retention of CYS graduates in SW Florida?" The second question was: "How has the experience you have acquired in the internship influenced your decision to either leave or stay in SW Florida?" Question three was: "In your opinion, what are 
Ndiangui, P. (2021). From Brain Drain to Brain Gain: The Battle Against Talent Drain

the main factors that make CYS majors leave SW Florida to seek opportunities elsewhere?" Question four was: "What should be done to increase the number of Child and Youth Studies graduates who choose to remain in SW Florida?" Below is the analysis of the responses of each of these questions.

Q1. What do you think should be done to increase the retention of CYS graduates in SW Florida?

It was evident that economic forces contributed most to the decision to either stay or leave the region. The majority of the participants stated "more job opportunities" or "better wages" as their responses to this question.

The students who joined the program after not passing the subject tests may sometimes feel that this is a lesser degree for those who have failed elsewhere. One student noted, "There is a stigma associated with being a CYS student - that is people are in this major because they can't pass the subject tests." There is therefore the need to market this innovative program more so that it is not seen as a choice for those who have failed elsewhere.

One participant said, "I think that the major needs to do a better job of marketing CYS as a degree that is meaningful in all of the areas in which it is valuable; social work, preschool, etc. There is so much that one can do with this major." Inevitably, there is a need to market this major more aggressively. The need to market the programs more aggressively has been highlighted by a number of other scholars (Groen, 2004; Hone \& El Said, 2016; Winters, 2011). It helps communities learn how helpful the CYS graduates can be. In addition, marketing helps the growth of the program itself.

Q2. How has the experience you have acquired in the internship influenced your decision to either leave or stay in SW Florida?

About $80 \%$ of all participants noted that they loved their internships; $65 \%$ of those who stayed stated that their internship experience helped them make the final decision. One respondent said, "After my internship, I stayed in SWFL for one year working at an ABA clinic. I did not want to transition right into grad school until I had some experience. That is the reason why I stayed to work in the same area I had done my internship."

It is also interesting to note that $32 \%$ of all respondents stated that they pursued a career different from the one they initially had in mind before the internship. One of the participants commented, "[I] enjoyed my internship, but it pushed me to pursue more of a career inside of the classroom rather than outside of one." Another respondent stated, "I'm currently working at my internship but looking to change fields."

Q3. What are the main factors that make CYS majors leave SW Florida to seek opportunities elsewhere? 
Ndiangui, P. (2021). From Brain Drain to Brain Gain: The Battle Against Talent Drain

The majority of the students stated that higher pay elsewhere made them choose to leave the region. It is therefore important for the local public and private organizations to work toward making incomes more competitive. The lack of recreational opportunities was cited as a significant factor leading to many CYS graduates to leave the region. One student stated that "There is nothing for a young adventurous person to do here." There is a need to identify recreation opportunities for these young people. Melton (2014) observed that in order to increase the retention of college graduates, there is a need to adjust city planning to millennial tastes. This would involve the initiation of more park related activities. Cities should also involve the youth in decision-making.

Many graduates also noted that they were not aware of the economic opportunities available for them in the region. One student stated, "I also believe it was unclear for me what my opportunities were in SWFL." This observation was also made by Soon (2010) in Chicago. Melton (2014) observed that connecting college students to local jobs will also increase retention. Winters (2011) noted that the growth of smart cities tend to be faster in areas with progressive higher education institutions that have built better connections with local communities and employers.

Q4. What should be done to increase the number of Child and Youth Studies graduates who choose to remain in SW Florida?

Marketing of the program is a crucial factor. It was evident that many businesses did not know much about the CYS program. One participant stated, "I believe this program can be appealing to others by clearly depicting what further opportunities you have with it."

The way the internship is structured is important. Students should be supported to get paid internships. Colleges should find ways of supporting the interns financially. It is also important for the interns to work more closely with possible future employers.

Several students also pointed out that CYS faculty should work closely with the local leadership so that the students would work more closely with cities and counties in the region. Melton (2014) pointed out that establishment of millennial advisory boards would help in having the young graduates have a buy-in and hence increase retention.

Students carrying out social entrepreneurial projects should be supported by the community and local public administration. This will increase innovation and smart city growth. Melton (2014) noted that there should be increased support for entrepreneurial incubators.

\section{Discussion}

The study pointed out that, as in many other cities, the CYS graduates are often forgotten in decision-making due to the city being "stuck in their older ways." Like other young adults, they require opportunities after they achieve their degree to cultivate innovation and creativity. These are ideally hands-on experiences that take advantage of this generation's general 
Ndiangui, P. (2021). From Brain Drain to Brain Gain: The Battle Against Talent Drain

willingness to become involved in the community and harvest solutions. Since quality of place is important to young adults, SW Florida cities need to seek out ways to accommodate such experiences for graduates to attract and retain them. The commonly cited retention factors were more jobs, increase in incomes, more affordable housing, and better recreational opportunities (Moretti, 2004). These four factors were commonly cited by the participants.

From the responses in the open-ended questions, it was observed that CYS graduates who worked in organizations that provided support during their internship had a greater likelihood of staying in the region. This is in line with the observation by Dickinson (2002), who observed that the graduates who had a good experience when working with local organizations tended to stay. In order to increase retention, it is therefore important for colleges to build a strong relationship with community partners in order to make the internships more enjoyable.

Another important factor highlighted in the open-ended responses was the interaction during the internship. Students who had positive interactions with the site supervisors and college advisors tended to stay in the region upon graduation. This was also observed by Hone \& El Said (2016) in a study on retention of course graduates in Egypt.

\section{Conclusion, Implications, and Recommendations}

In spite of all the talk about how mobile young college graduates are, it has been noted from both the research and the literature that, given a choice, the bulk of them would prefer to stay in the familiar grounds where they went to school (Florida, 2016). For that reason, it should be the responsibility of local regions to examine ways and means of retaining the local college graduates. In this study, it was noted that several graduates from the CYS program of Florida Gulf Coast University initially leave SW Florida only to return after less than two years. This is particularly true of those who were born in the state of Florida. A significant number of those who joined the program from out of state tend to stay in the region. The majority attribute their stay to the job opportunities and favorable weather conditions.

Like in any other program, there is no doubt that the increase in proper marketing of the program is a win-win for all. Increased communication will help organizations and future employers know what the college programs are providing. Hone and El Said (2016) considered this to be a crucial factor of retention; they observed that businesses are ready to fund a program whose graduates will be more helpful to them. In the process, the program also benefits by having an increased number of students selecting it as a major.

There are many other suggestions made by the participants who were opting to leave the local region. For instance, they noted that the city should have more parks and recreation areas. The park should also be more attractive and welcoming to young families. They mentioned that since the region tends to be too hot sometimes, there should be more shaded areas. The river revitalization has been done well, but having more welcoming itinerant pedestrian businesses like ice cream parlors and food booths would increase attractiveness. 
Ndiangui, P. (2021). From Brain Drain to Brain Gain: The Battle Against Talent Drain

SW Florida should make a conscious effort to attract more local graduates by rebranding the public transport system. Graduates who are not in a position to buy or maintain cars may need a faster and easier-to-navigate public transport system. Introduction of cheap scooters will make movement within the city easier. A bike-sharing system would also be very attractive to the graduates who are starting to settle down in the region. The public bus system may need more interconnecting routes.

Lastly, participants pointed out that affordable housing is also a factor that needs urgent attention. The rents tend to be prohibitive in the more lucrative parts of the city. Students are therefore forced to seek housing in areas far from their places of work, which again increases their transport costs. Getting a rental property is also difficult due to the requirements of credit and deposits; most students graduate with student loans that create financial instability. This makes living in the region after graduation very difficult.

The implications of the research are many. The findings of this research project will be used to examine what public and private enterprises and nonprofit agencies need to do to retain the CYS graduates in SW Florida. The findings will be used in the meetings with representatives of these organizations in the region. The ultimate goal is that the retention rate (and consequent reduction of brain drain) of CYS graduates in SW Florida will be increased. The study initiates conversations on what needs to be done to increase the impact of the retained graduates in the socioeconomic development of the region.

\section{References}

Dickinson, N. S., \& Perry, R. E. (2002). Factors influencing the retention of specially educated public child welfare workers. Journal of Health \& Social Policy, 15(3-4), 89-103.

Duncan, G. J., \& Raudenbush, S. W. (1999). Assessing the effects of context in studies of child and youth development. Educational Psychologist, 34(1), 29-41.

Fallah, B., Partridge, M. D., \& Rickman, D. S. (2013). Geography and high-tech employment growth in US counties. Journal of Economic Geography, 14(4), 683-720.

FGCU College of Education Website:

https://www.fgcu.edu/coe/programs/undergraduateprograms/childandyouthstudies-bs

Florida, R. (2016). The U.S. cities winning the battle against brain drain. Retrieved from http://www.digital.nyc/news/us-cities-winning-battle-against-brain-drain

Glaeser, E. L., Scheinkman, J., \& Shleifer, A. (1995). Economic growth in a cross-section of cities. Journal of Monetary Economics, 36(1), 117-143. 
Ndiangui, P. (2021). From Brain Drain to Brain Gain: The Battle Against Talent Drain

Hone, K. S., \& El Said, G. R. (2016). Exploring the factors affecting MOOC retention: A survey study. Computers \& Education, 98, 157-168.

Lima, A. (2014). Retaining recent college graduates in Boston: Is there a brain drain? Retrieved from http://www.bostonplans.org/getattachment/f3228899-e69d-43d8-b64e-90b2932db1ac

Melton, A. (2014). Attracting \& retaining college graduates: A student-driven model.

Retrieved from

http://media.mlive.com/grpress/news_impact/other/Attracting\%20and\%20Retaining\%20Coll ege\%20Graduates\%20\%20A\%20Student-Driven\%20Model.pdf

Miguélez, E., \& Moreno, R. (2014). What attracts knowledge workers? The role of space and social networks. Journal of Regional Science, 54(1), 33-60.

Moretti, E. (2004). Estimating the social return to higher education: Evidence from longitudinal and repeated cross-sectional data. Journal of Econometrics, 121(1-2), 175-212.

Moretti, E. (2012). The new geography of jobs. Houghton Mifflin Harcourt.

Noble, K., Flynn, N. T., Lee, J. D., \& Hilton, D. (2007). Predicting successful college experiences: Evidence from a first year retention program. Journal of College Student Retention: Research, Theory \& Practice, 9(1), 39-60.

Paulsen, M. B. (1990). College choice: Understanding student enrollment behavior. ASHE-ERIC Higher Education Report No. 6. ASHE-ERIC Higher Education Reports, The George Washington University.

Rothwell, J. (2015). What colleges do for local economies: A direct measure based on consumption. Washington, DC: Brookings Institute.

Schmidt, P. (1998). More states try to stanch "brain drains," but some experts question the strategy.

Retrieved from https://www.chronicle.com/article/More-States-Try-to-Stanch/97721

Trippl, M. (2013). Scientific mobility and knowledge transfer at the interregional and intraregional level. Regional Studies, 47(10), 1653-1667.

U.S. News Report. (2019). Florida best in nation for higher education, report says. https://www.nbcmiami.com/news/local/Florida-Best-In-Nation-for-Higher-Education-Rep ort-Says-509918451.html

Winters, J. V. (2011). Why are smart cities growing? Who moves and who stays. Journal of Regional Science, 51(2), 253-270. 